\title{
John Stuart Mill: Über die Freiheit
}

Herausgegeben von

Michael Schefczyk und Thomas Schramme 


\section{Inhalt}

Michael Schefczyk und Thomas Schramme

1 Einleitung - 1

Jonathan Riley

2 The Right to Liberty — 11

Peter Niesen

3 Uber die Freiheit des Denkens und der Diskussion - 33

Thomas Schramme

4 Das Ideal der Individualităt und seine Begründung — 55

\section{Markus Stepanians}

5 Mills deontische Konkretisierung des Freiheitsprinzips -75

Jean-Claude Wolf und Catherine Buchmüller-Codoni

6 Freiheit durch Erziehung und Erziehung zur Freiheit - 93

Michael Schefczyk

7 ,Grounds different from, though equally solid with ${ }^{\text {" }}$ - Wirtschaftliche und gesellschaftliche Freiheit in On Liberty — 115

Frauke Höntzsch

8 Vorgeschichte und Querverbindungen: Der Einfluss Benthams und Humboldts auf Mill -137

Christoph Schmidt-Petri

9 Freiheit, Paternalismus und die Unterwerfung der Frauen — 159

Otfried Höffe

10 Ein systematischer Rückblick auf John Stuart Mills Denken — 181

Auswahlbibliographie -193

Personenregister — 199

Sachregister — 201

Hinweise zu den Autorinnen und Autoren — 205 